\title{
Estimation of Grain Size Distribution of Friction Stir Welded Joint by using Ma- chine Learning Approach
}

\author{
Akshansh Mishra $^{\mathrm{a}}$, Tarushi Pathak ${ }^{\mathrm{b}}$ \\ ${ }^{a}$ Department of Mechanical Engineering, Politecnico Di Milano, Milan,Italy \\ ${ }^{\mathrm{b}}$ Computer Sciences Department, SRM Institute of Science and Technology, Kattangulathur, India \\ akshansh.frictionwelding@gmail.com, tarushipathak@gmail
}

Friction Stir Welding; Machine Learning; Grain Size; Python Programming
Machine learning has widely spread in the areas of pattern recognition, prediction or forecasting, cognitive game theory and in bioinformatics. In recent days, machine learning is being introduced into manufacturing and material industries for the development of new materials and simulating the manufacturing of the required products. In the recent paper, machine learning algorithm is developed by using Python programming for the determination of grain size distribution in the microstructure of stir zone seam of Friction Stir Welded magnesium AZ31B alloy plate The grain size parameters such as an equivalent diameter, perimeter, area, orientation etc. were determined. The results showed that the developed algorithm is able to determine various grain size parameters accurately.

\section{Introduction}

The development of various Artificial Intelligence applications is made possible by the usage of Machine Learning algorithms. In the available set of a massive amount of data, the Machine learning model uses a statistical technique to derive the required pattern. The Machine Learning model generally feeds on digitally available data which is composed of numbers, images, videos, or texts. Machine Learning algorithms generally operate on low-level tasks in which raw data is processed and is further acquired by an Artificial Intelligence-based system. The Machine Learning model generally feeds on digitally available data which is composed of numbers, images, videos, or texts. Machine Learning algorithms generally operate on low-level tasks in which raw data is processed and is further acquired by an Artificial Intelligence-based system. The Machine Learning algorithm's working principle is based on three points. Firstly, a hypothesis of a certain phenomenon is formulated. Secondly, to test the hypothesis i.e. for the validation of the chosen model, a dataset is collected. Thirdly, the given hypothesis is refined by iterating it. 
Traditional manufacturing processes are being spiced up by the introduction of various Machine Learning algorithms in their applications. For example, GE research is combining artificial intelligence and machine learning models with "physics" to inspection, processing, and advanced manufacturing design to obtain the real-world product [1]. Li et al used a data-driven machine learning model approach for predicting the surface roughness of an additively manufactured part. It was observed that the developed machine learning model was able to predict the surface roughness with good accuracy [2]. Moreno et al. proposed an image processing and machine learning model based on the Random Forest algorithm for automatic classification of pores present in Al-alloys by laser melt deposition. The proposed model resulted in an accuracy of $94.41 \%$ [3]. Kopper et al. predicted the mechanical property i.e. Ultimate Tensile Strength (UTS) of high-pressure die-cast Al-alloy component by using various regression machine learning models like Support Vector Machines (SVM), XG Boost, and Random Forest algorithm [4].

Machine Learning algorithms are also finding applications in solid-state welding processes like Friction Stir Welding (FSW). Unlike other conventional welding processes, Friction Stir Welding does not use any filler material for joining purposes. Friction Stir Welding tool which is harder than the base material to be joined is used. The schematic representation of the Friction Stir Welding process is shown in Figure 1 [5]. Verma et al. [6] used three machine learning models i.e. Artificial Neural Network, Random Forest, and M5P tree regression for analyzing and predicting the tensile behavior of aviation-grade aluminum alloy friction stir welded joint. It was observed from results that the Random Forest algorithm model outperforms the other two models in terms of predicting the tensile behavior accurately. Hartl et al. [7] used three Artificial Neural Network models i.e. Convolutional Neural Networks, Feedforward fully connected Neural Networks, and Recurrent Neural Networks for predicting the surface quality of friction stir welded EN AW-6082 T6 sheets. Out of these three used Artificial Neural Networks, Convolutional Neural Networks achieved the highest classification accuracy. Srinivasan et al. [8] improved the degraded microstructure of the friction stir welded joint by using a hybrid sparsity machine learning model. 


\section{Sufficient downward force to maintain registered contact}

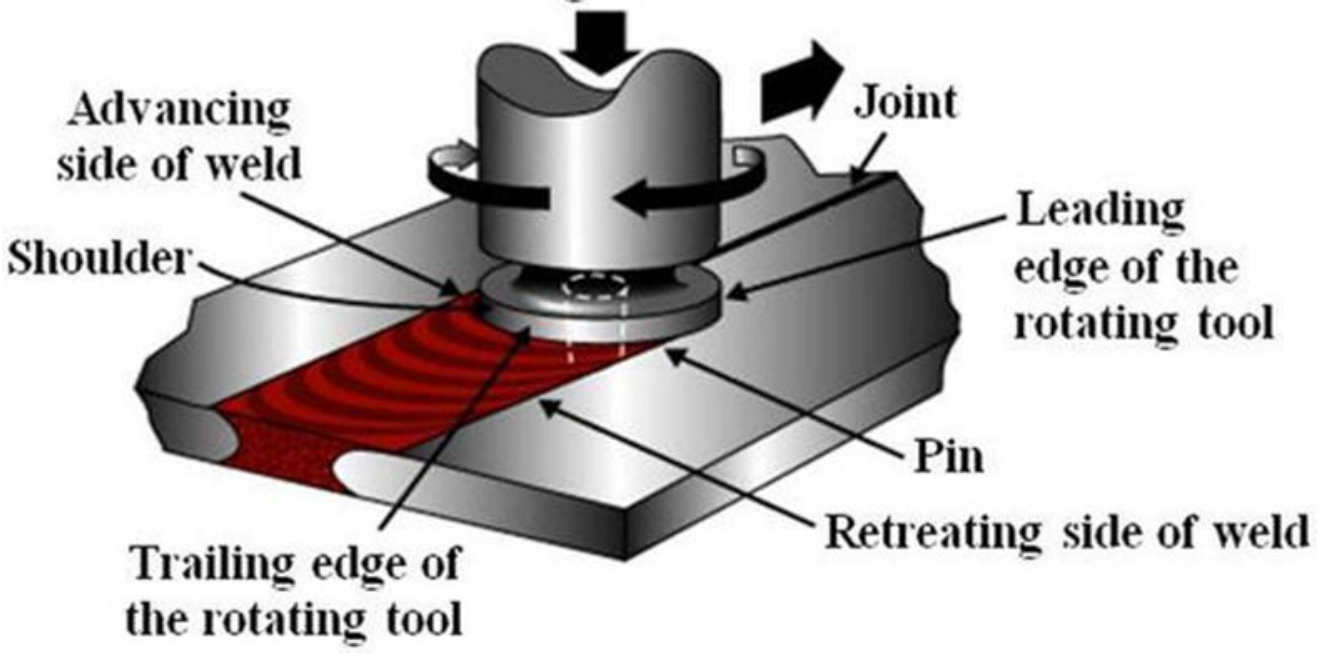

Figure 1. Working Mechanism of Friction Stir Welding process [5].

In the recent study, a machine learning algorithm has been developed for the study of grain size distribution in the microstructure of stir zone seam of Friction Stir Welded magnesium AZ31B obtained by Subramani et al [9].

\section{Material and Methods}

In the experiment, AZ31 B Magnesium alloy plates (commercial) of $6 \mathrm{~mm}$ thickness were joined by Friction Stir Welding process [9]. The weld plates were in the dimensions of $100 \mathrm{~mm}$ length and $75 \mathrm{~mm}$ width. SiC nanoparticles were incorporated and compacted in the grooves of width $0.3,0.6,0.9,1.2$, and $1.5 \mathrm{~mm}$, of the corresponding volume percentages were indicated as V4, V8, V12, V16, and V20, respectively. The schematic diagram of volume fraction sample is shown in the Figure 2. 


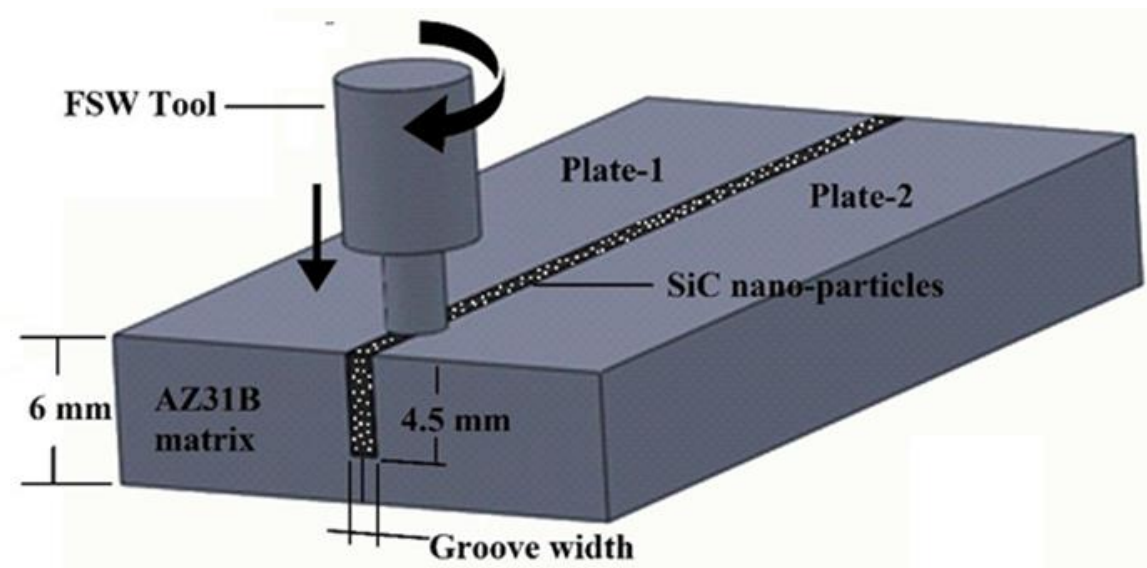

Groove width $0.3,0.6,0.9,1.2$ and $1.5 \mathrm{~mm}$

Figure 2: Volume fraction sample [9].

The process parameter of the experimentation is shown in the Table 1.

Table 1. Friction stir welding (FSW) process parameters used in this study.

\begin{tabular}{cc}
\hline Control Parameters & Values \\
\hline Tool rotational speed, N $(\mathrm{rpm})$ & $1250 \mathrm{rpm}$ \\
Tool travel rate, $\mathrm{F}(\mathrm{mm} / \mathrm{min})$ & $25 \mathrm{~mm} / \mathrm{min}$ \\
Volume percentage V $(\%)$ & $4(\mathrm{~V} 4), 8(\mathrm{~V} 8), 12(\mathrm{~V} 12), 16(\mathrm{~V} 16), 20(\mathrm{~V} 20)$ \\
Groove width $(\mathrm{W})$ & $0.3,0.6$, \\
$0.9,1.2,1.5 \mathrm{D} / \mathrm{d}$ ratio and Pin height in $\mathrm{mm}$ & 3 and \\
$5.7 \mathrm{~mm} \quad$ & Cylindrical threaded tool pin \\
Tool Pin profile & H13 tool steel \\
profile Tool material &
\end{tabular}


The optical microstructure of the matrix alloy (Figure3a) and base metal welded joint without nano$\mathrm{SiC}$ (Figure3b) is shown in Figure 3.

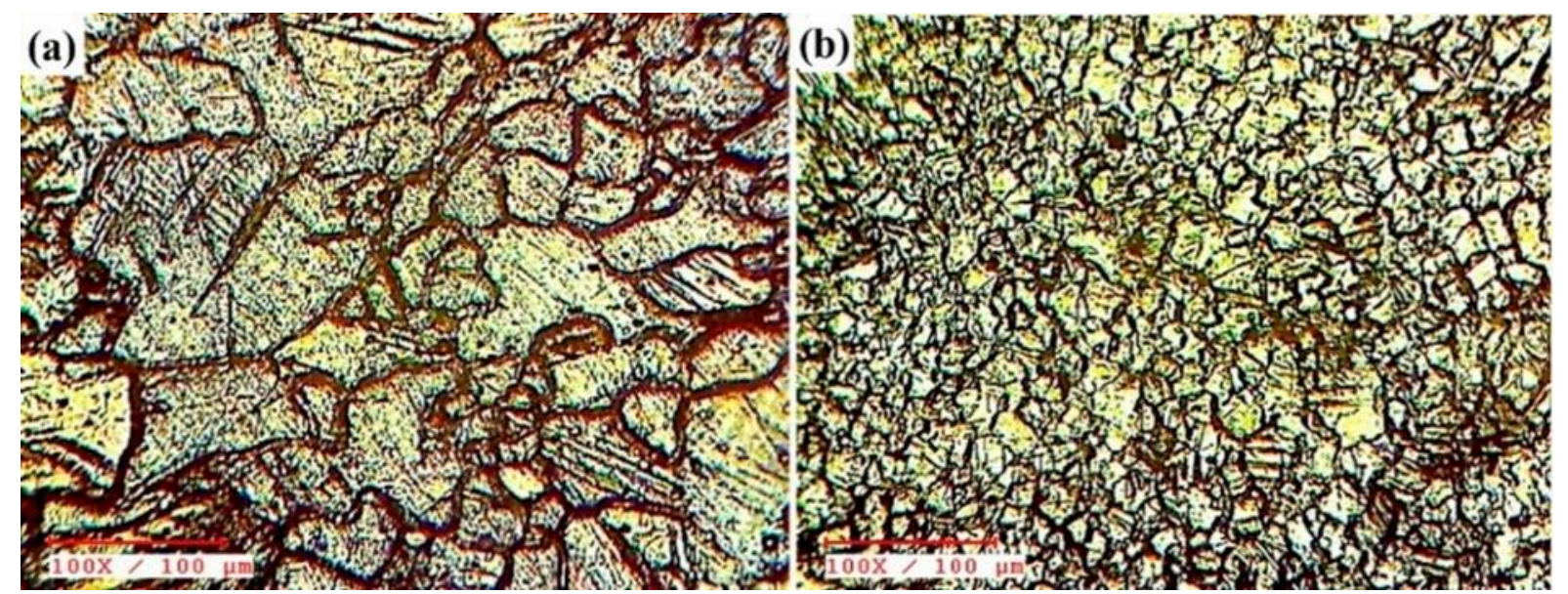

Figure 3. Optical microstructure: (a) as-received matrix alloy (b) FSW AZ31B joint (without reinforcement) [9].

Grain size distribution analysis is done by loading the above microstructures which have a whole bunch of grains and extracting some statistical features out of it. The given RGB image is converted to a grayscale image. It is important to define a particular scale in this case in order to track the size of the pixel while working on a microscopic image. The first step is to read an image and define pixel size state(if needed to convert results into microns, no pixels). The second step involves the denoising process if required and threshold image to separate grain from boundaries. Thirdly, image clean up is performed if needed and create a mask for observed grains in the microstructure. The fourth step involves the labeling of grains in the masked image. At the fifth stage, the measurement of the properties of each grain in the microstructure is performed. At the sixth and last stage, output results are obtained in the form of a CSV (Comma Seperated Values) file. 


\section{Results and Discussions}

The important Python programming libraries which were important for coding purpose are cv2, numpy, pyplot from matplotlib, ndimage, io, color to show images in the color library so we can assign a different color to grains, measure library to measure the grain size distribution. The image is read by indicating the file path, then the scale is defined which is 1 pixel $=0.5 \mu \mathrm{m}$ which is further multiplied to every measurements as shown in the Figure 4 and Figure 5. If the image has a scale bar in the microscope then the image needed to be cropped by slicing the dataset of an image array.

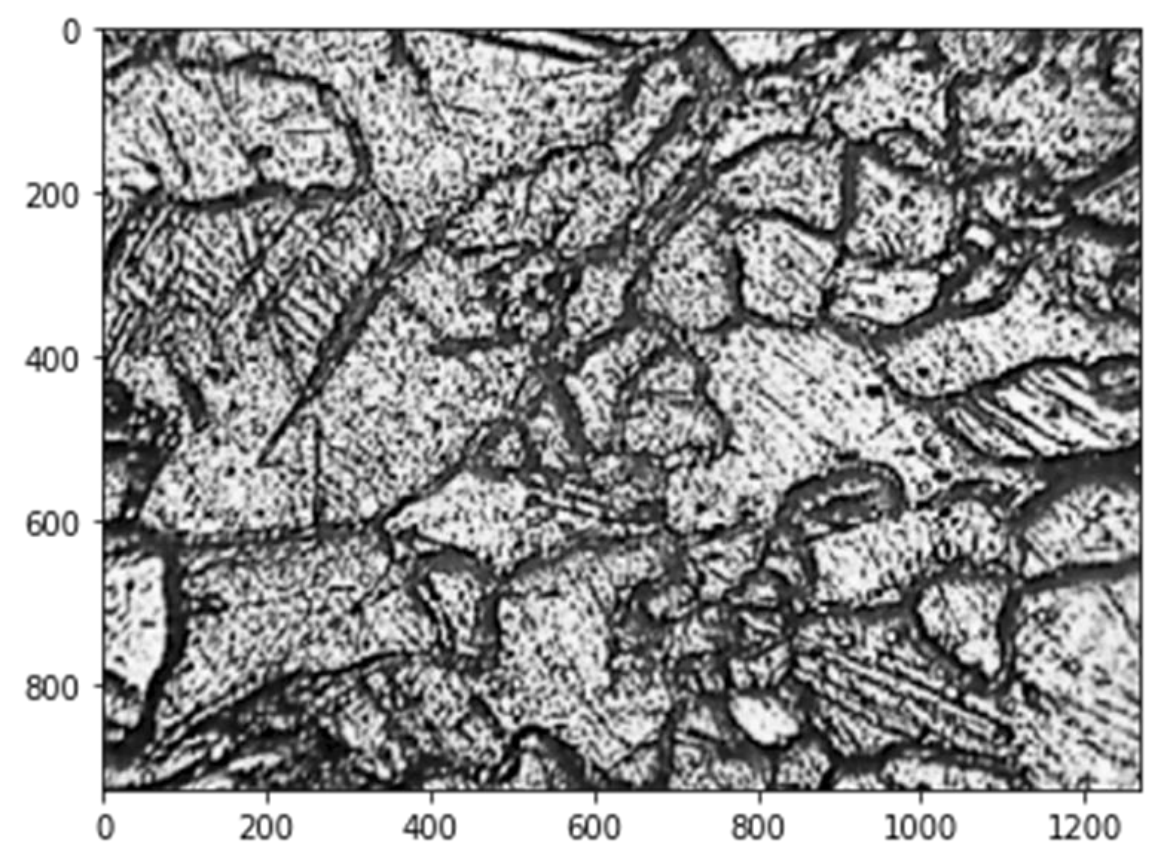

Figure 4. Loaded image of optical microstructure of received matrix alloy 


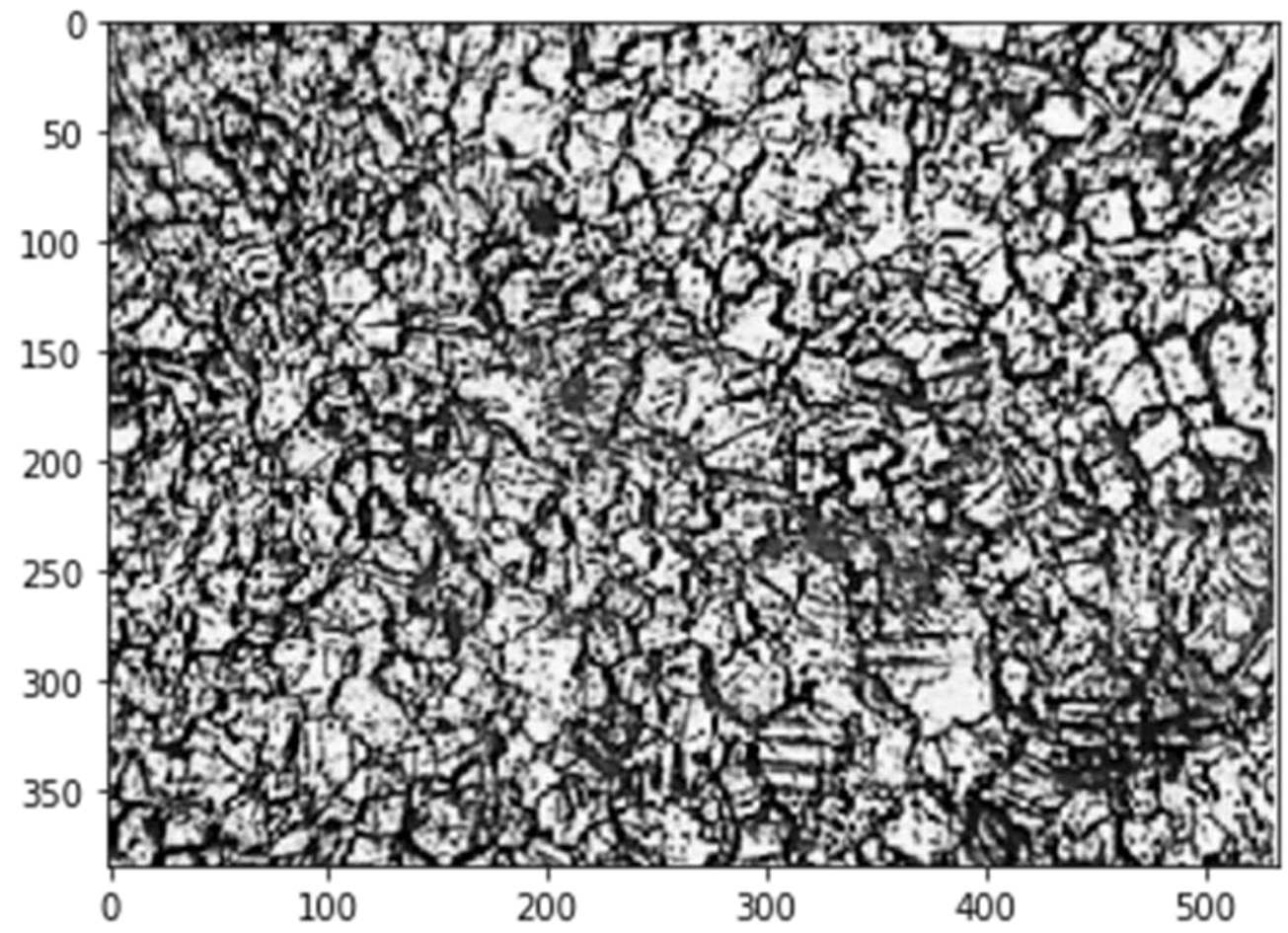

Figure 5. Loaded image of optical microstructure of FSW AZ31B joint (without reinforcement).

Step 1 of the thresholding is to look at the histogram itself as shown in Figure 6 and Figure 7. The loaded images are in form of a 2D array, so in order to obtain a histogram we need 1D array. So we need to flatten the image which takes a $2 \mathrm{D}$ image and flatten it to a $1 \mathrm{D}$ array of bins $=100$ and range $=(0,255)$. From Figure 6 it is observed that a bunch of pixels lies between 130-200 and From Figure 7 it is observed that a bunch of pixels lies between 60-200. 


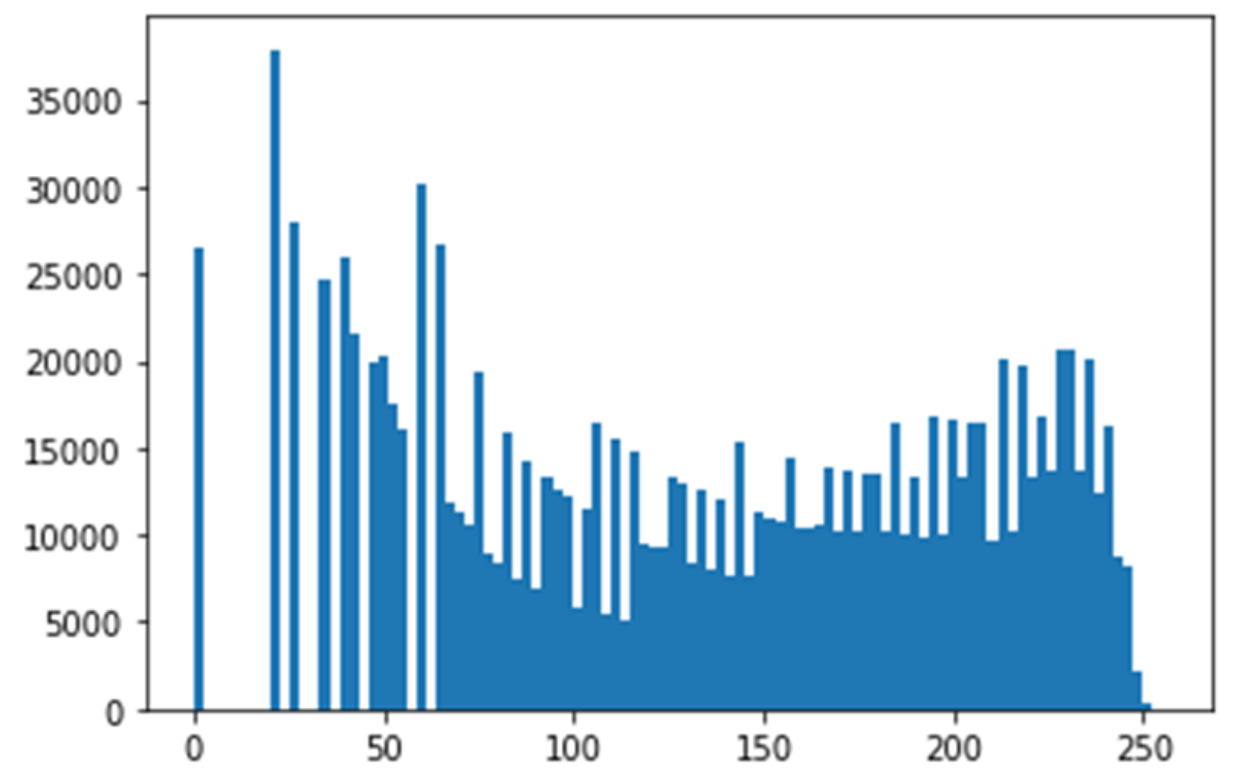

Figure 6. Histrogram distribution of optical microstructure of received matrix alloy

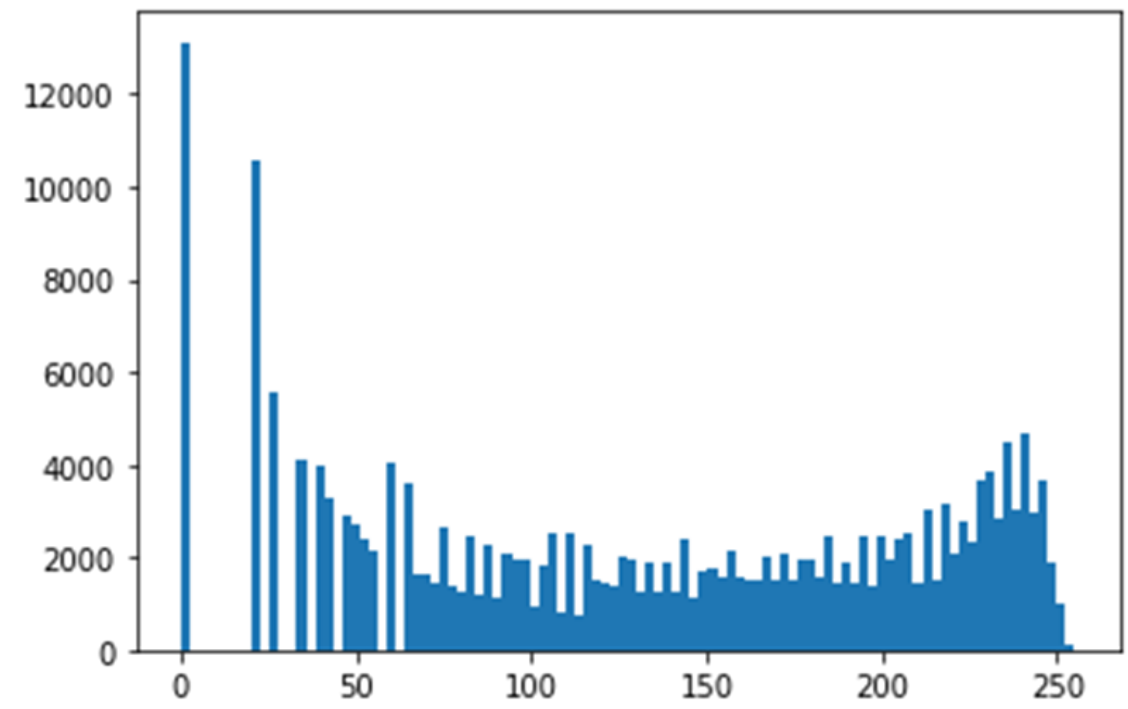

Figure 7. Histogram distribution of the optical microstructure of FSW AZ31B joint (without reinforcement). 
The two types of thresholding operation can be done i.e. either manual thresholding or auto thresholding. The threshold value obtained for the optical microstructure of received matrix alloy is 130 while thresholded value obtained for the optical microstrucutre of FSW AZ31B joint (without reinforcement) is 128. The obtained thresholded image for the optical microstrucutre of received matrix alloy and FSW AZ31B joint (without reinforcement) is shown in the Figure 8 and Figure 9.

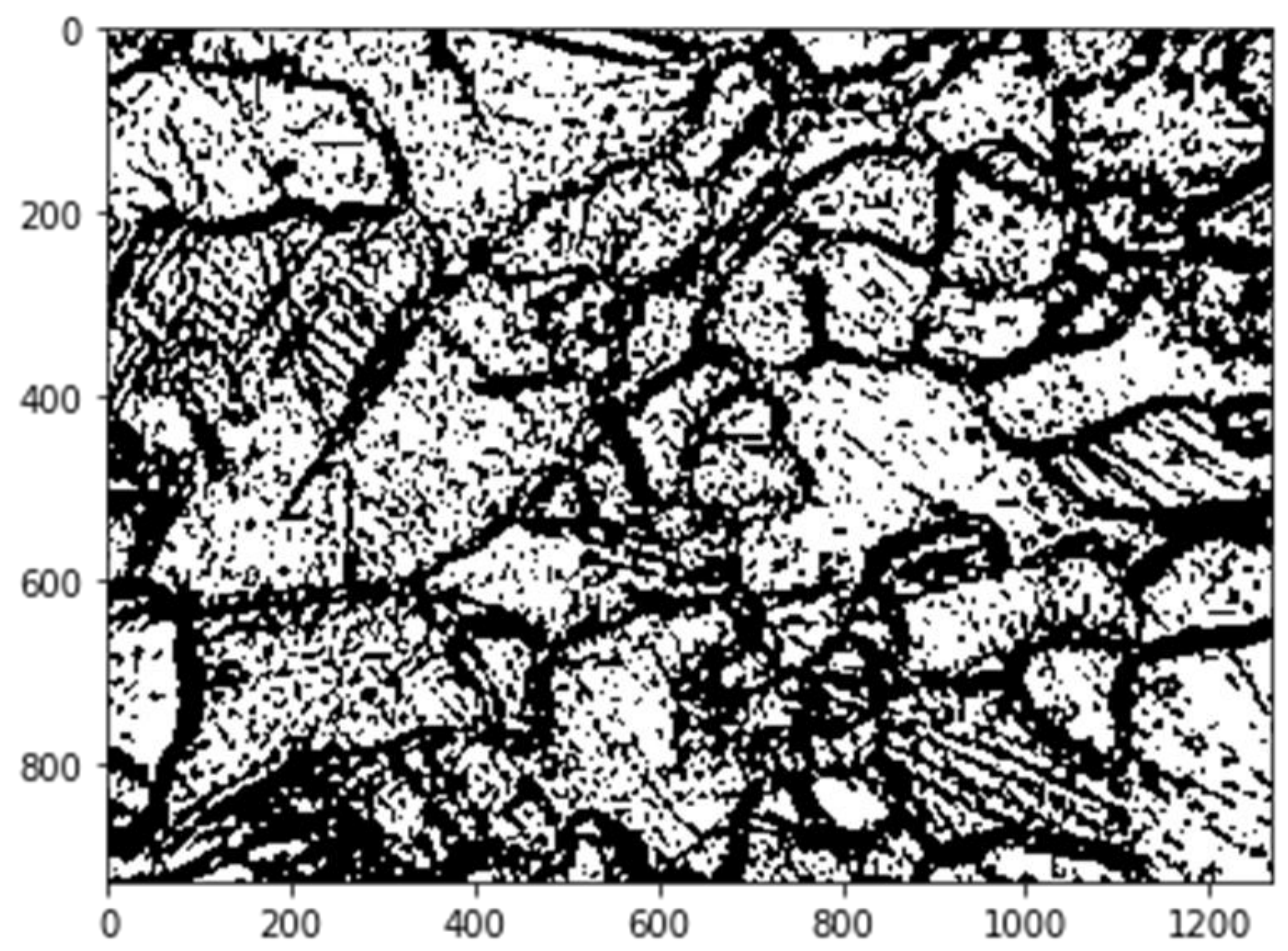

Figure 8 . Thresholded image of the optical microstructure of received matrix alloy 


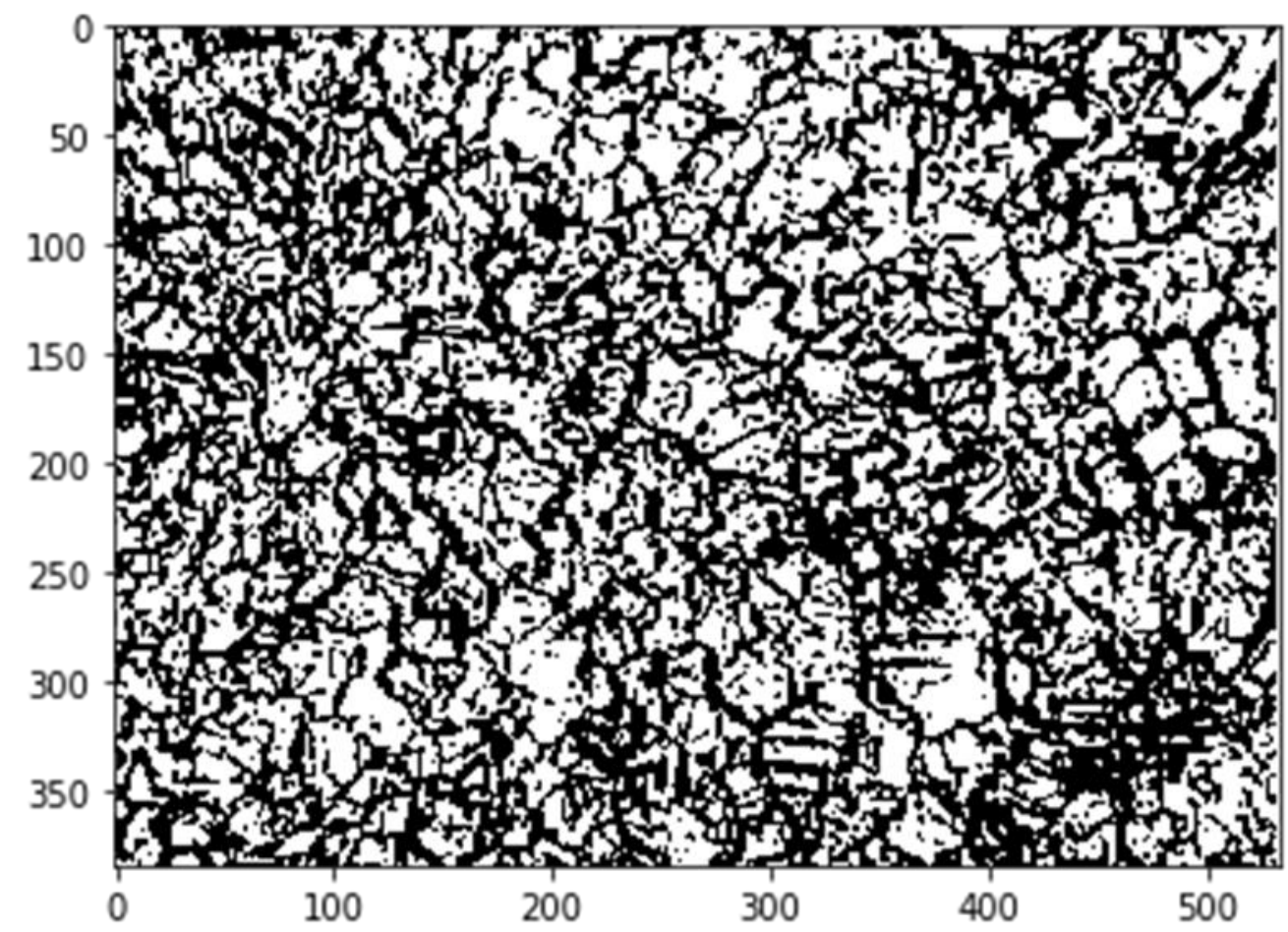
forcement).

Figure 9. Thresholded image of the optical microstructure of FSW AZ31B joint (without rein-

It is observed that all pixels corresponding to the grain will have a value of 255 and all pixels corresponding to the grain boundary have a value 0 . So this is only a threshold image, not a binary image. So, we need to convert this thresholded image to a binary image. The thresholded image shows some missing pixels, we can close these areas of the grain by eroding and dilating process. When we use the eroding process then the grain will shrink by 1 pixel and when we use dilating process they go up by 1 pixel. In order to execute eroding and dilating operation, we created kernel size of $(3,3)$ of type int 8 . Eroding and dilating operation is carried out on thresholded image. The thresholded image is nothing but 8-bit integer with all values of 255 and 0's. It is a binary image but the system doesn't know its a binary image. So it is converted to a binary image with the help of masking as shown in the Figure 10 and Figure 11. 


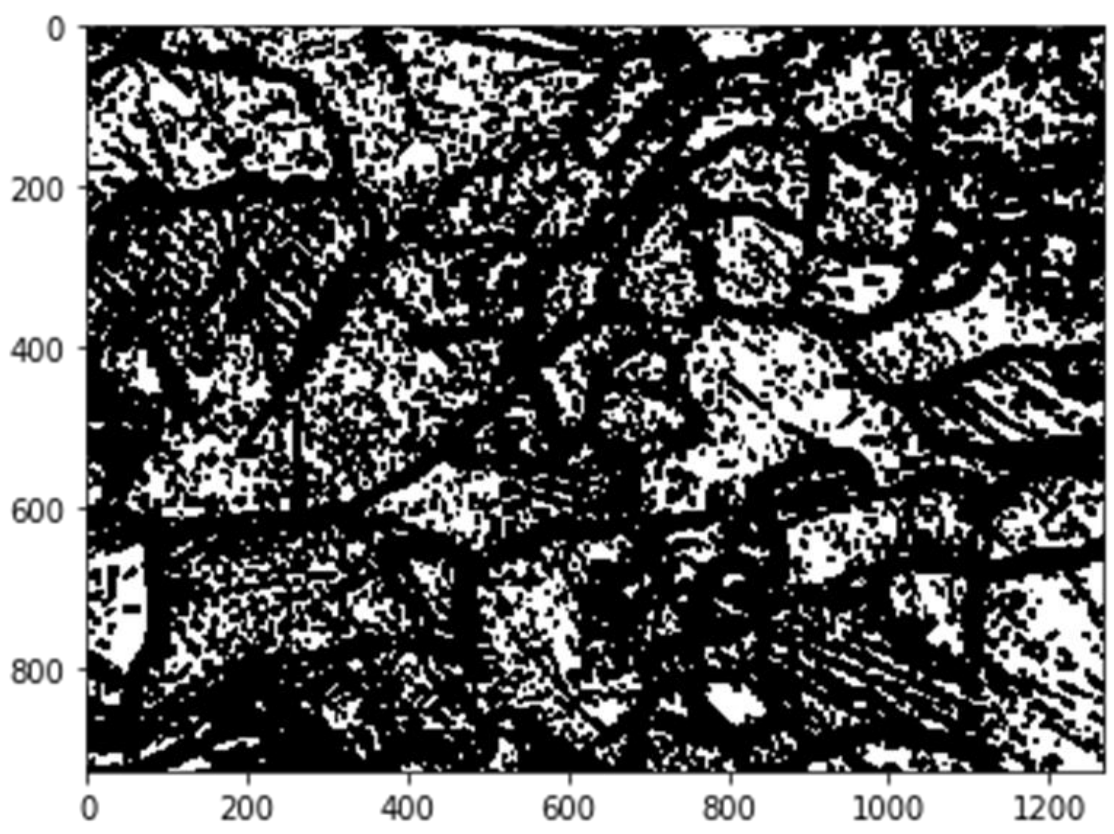

Figure 10. Masked image of the optical microstructure of received matrix alloy.

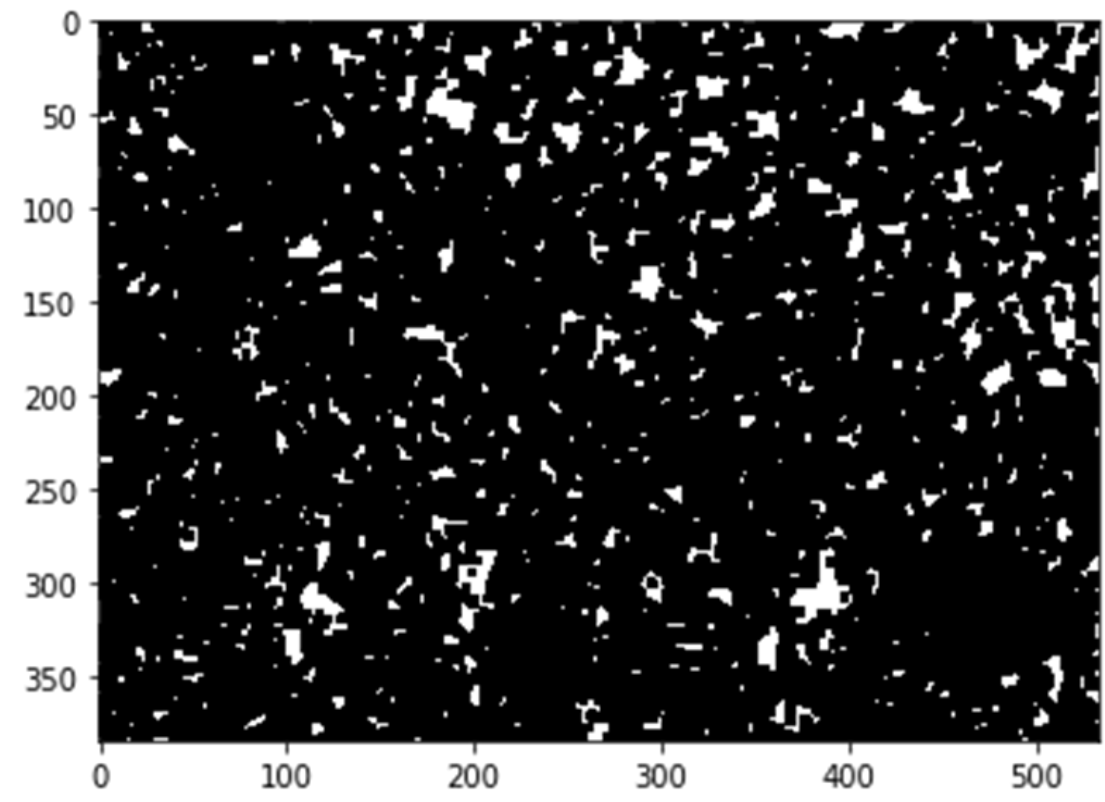

Figure 11. Masked image of optical microstructure of FSW AZ31B joint (without reinforcement). 
Each grain is labeled in the masked image as shown in Figure 12 and Figure 13. Structure factor of $[[1,1,1],[1,1,1],[1,1,1]]$ is used to define the nature of pixel connection i.e. whether connected or disconnected. In the ndimage library, there is a function called label which labels the unconnected grains. Label assignment is done through the masked image and assigns a value to the all unconnected objects.

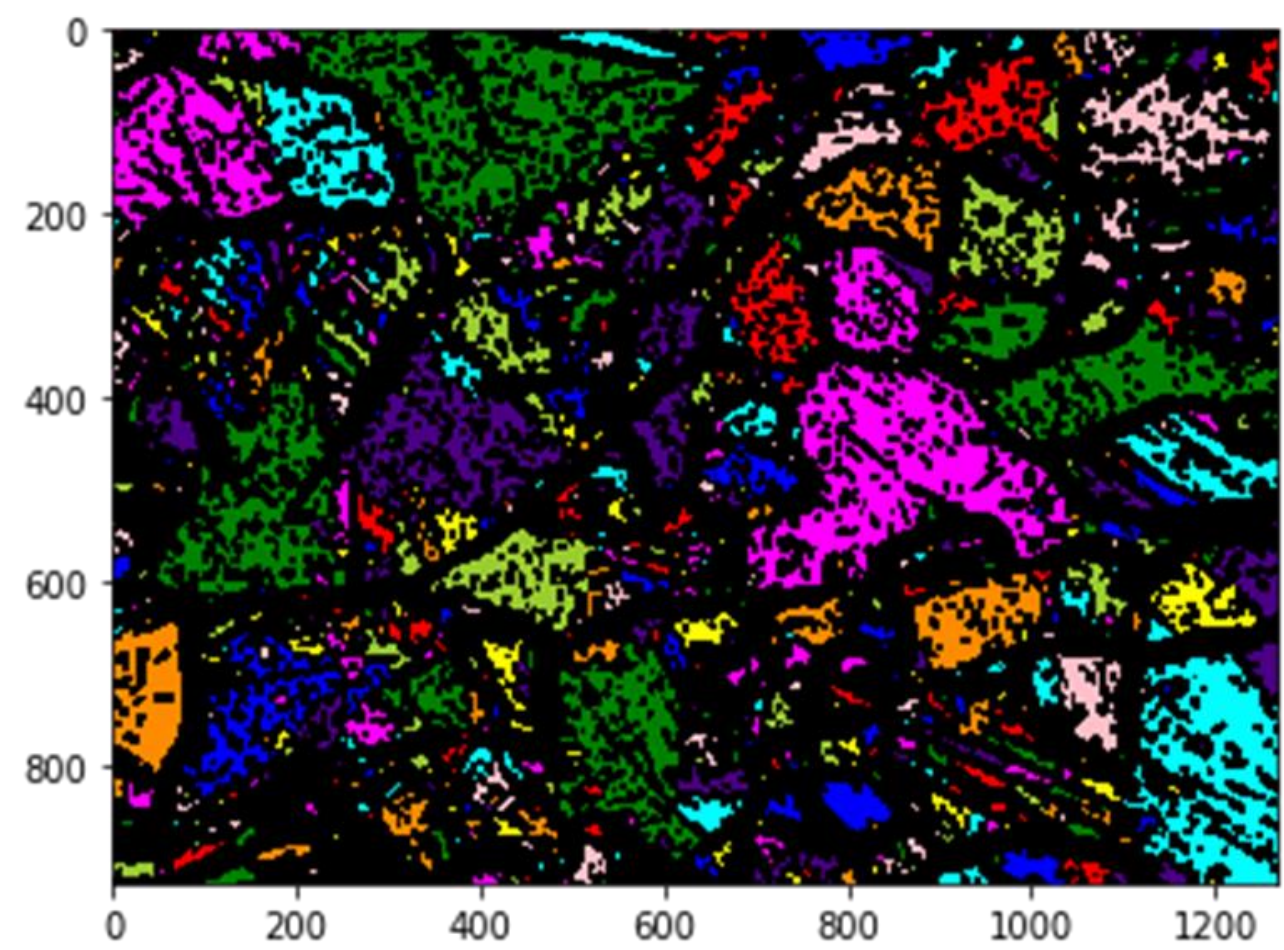

Figure 12. Labeled image of the optical microstructure of received matrix alloy 


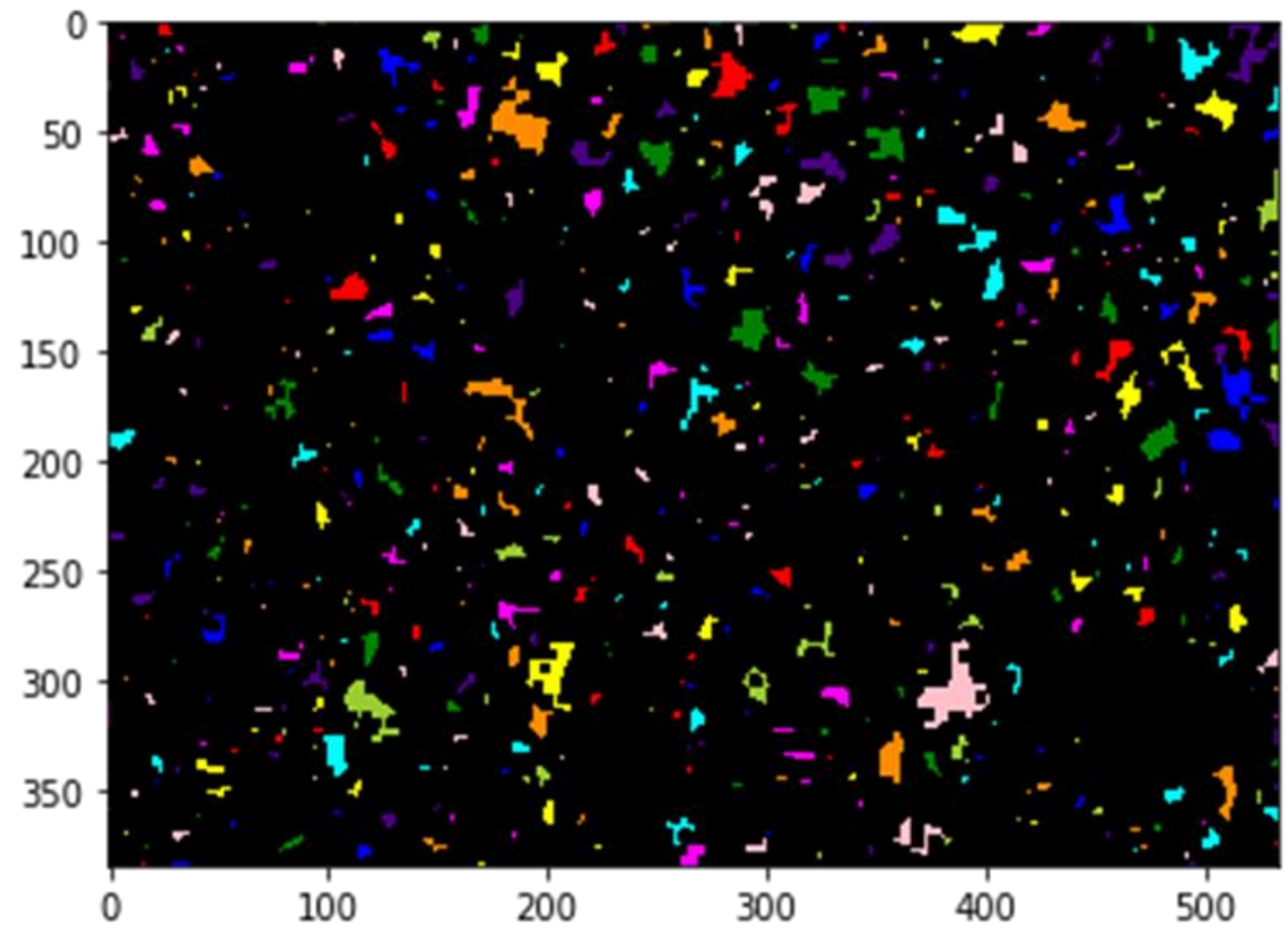

Figure 13. Labeled image of the optical microstructure of FSW AZ31B joint (without reinforcement).

Measuring the grain property is done by the extraction of property from each labeled image. The obtained measurement of grain size distribution of the optical microstructure of the received matrix alloy and FSW AZ31B joint (without reinforcement) is shown in the Table 2 and Table 3 . Table 2 obtained as a CSV file has 1296 grain distribution properties of the optical microstructure of received matrix alloy out of which only 10 is shown in the Table 2 (rest can be further found in supplementary file) while Table 3 has 696 grain distribution properties out which only 10 is shown in the Table 3 (rest in supplementary file). 
Table 2: Grain Size distribution Property of received metal matrix alloy

\begin{tabular}{|c|c|c|c|c|c|c|c|c|c|}
\hline $\begin{array}{l}\text { Grain } \\
\text { Num- } \\
\text { ber }\end{array}$ & $\begin{array}{l}\text { Equiva- } \\
\text { lent Di- } \\
\text { ameter }\end{array}$ & $\begin{array}{l}\text { Orienta- } \\
\text { tion }\end{array}$ & $\begin{array}{l}\text { Major } \\
\text { Axis }\end{array}$ & $\begin{array}{l}\text { Minor } \\
\text { Axis }\end{array}$ & $\begin{array}{l}\text { Perim- } \\
\text { eter }\end{array}$ & Area & $\begin{array}{l}\text { Min } \\
\text { Inten- } \\
\text { sity }\end{array}$ & $\begin{array}{l}\text { Mean } \\
\text { Inten- } \\
\text { sity }\end{array}$ & $\begin{array}{l}\text { Max } \\
\text { Inten- } \\
\text { sity }\end{array}$ \\
\hline 1 & $\begin{array}{l}4.5834978 \\
44\end{array}$ & $\begin{array}{r}76.241 \\
38617\end{array}$ & $\begin{array}{r}7.91 \\
1677\end{array}$ & $\begin{array}{r}3.34 \\
9746\end{array}$ & $\begin{array}{r}17.4 \\
1421\end{array}$ & $\begin{array}{r}16 . \\
5\end{array}$ & 184 & $\begin{array}{r}217 . \\
3333\end{array}$ & 234 \\
\hline 2 & $\begin{array}{r}2.6462 \\
83714\end{array}$ & $\begin{array}{r}42.66053 \\
638\end{array}$ & $\begin{array}{r}3.28 \\
4856\end{array}$ & $\begin{array}{r}2.28 \\
4291\end{array}$ & $\begin{array}{r}8.12 \\
132\end{array}$ & 5.5 & 138 & $\begin{array}{r}159 . \\
4091\end{array}$ & 178 \\
\hline 3 & $\begin{array}{r}3.2410 \\
22407\end{array}$ & $\begin{array}{r}17.795 \\
39566\end{array}$ & $\begin{array}{r}3.86 \\
4296\end{array}$ & $\begin{array}{r}2.74 \\
9772\end{array}$ & $\begin{array}{r}9.82 \\
8427\end{array}$ & $\begin{array}{r}8.2 \\
5\end{array}$ & 180 & $\begin{array}{r}208 . \\
1212\end{array}$ & 225 \\
\hline 4 & $\begin{array}{r}22.546 \\
41631\end{array}$ & $\begin{array}{r}- \\
87.87354 \\
752\end{array}$ & $\begin{array}{r}59.2 \\
9705\end{array}$ & $\begin{array}{r}18.5 \\
4393\end{array}$ & $\begin{array}{r}259 . \\
4858\end{array}$ & $\begin{array}{r}39 \\
9.25\end{array}$ & 138 & $\begin{array}{r}214 . \\
2918\end{array}$ & 251 \\
\hline 5 & $\begin{array}{r}88.073 \\
22872\end{array}$ & $\begin{array}{r}83.002 \\
13477\end{array}$ & $\begin{array}{r}190 . \\
3864\end{array}$ & $\begin{array}{r}102 . \\
7502\end{array}$ & $\begin{array}{r}364 \\
2.112\end{array}$ & $\begin{array}{r}60 \\
92.25\end{array}$ & 131 & $\begin{array}{r}216 . \\
7196\end{array}$ & 253 \\
\hline 6 & $\begin{array}{r}2.7057 \\
5819\end{array}$ & $\begin{array}{r}84.64231 \\
874\end{array}$ & $\begin{array}{r}4.73 \\
0204\end{array}$ & $\begin{array}{r}1.53 \\
8244\end{array}$ & $\begin{array}{r}8.70 \\
7107\end{array}$ & $\begin{array}{r}5.7 \\
5\end{array}$ & 192 & $\begin{array}{r}218 . \\
7391\end{array}$ & 240 \\
\hline 7 & $\begin{array}{r}0.7978 \\
84561\end{array}$ & 0 & 1 & 0 & 0 & 0.5 & 165 & 169 & 173 \\
\hline 8 & $\begin{array}{r}18.220 \\
79063\end{array}$ & $\begin{array}{r}77.788 \\
18815\end{array}$ & $\begin{array}{r}60.8 \\
2087\end{array}$ & $\begin{array}{r}6.83 \\
4718\end{array}$ & $\begin{array}{r}140 . \\
9264\end{array}$ & $\begin{array}{r}26 \\
0.75\end{array}$ & 157 & $\begin{array}{r}229 . \\
8102\end{array}$ & 249 \\
\hline 9 & $\begin{array}{r}3.3377 \\
90589\end{array}$ & $\begin{array}{r}85.655 \\
51415\end{array}$ & $\begin{array}{r}7.37 \\
0103\end{array}$ & $\begin{array}{r}1.59 \\
0775\end{array}$ & $\begin{array}{r}13.7 \\
0711\end{array}$ & $\begin{array}{r}8.7 \\
5\end{array}$ & 175 & $\begin{array}{r}210 . \\
3143\end{array}$ & 227 \\
\hline 10 & $\begin{array}{r}4.8533 \\
4231\end{array}$ & $\begin{array}{r}83.956 \\
76619\end{array}$ & $\begin{array}{r}11.4 \\
5849\end{array}$ & $\begin{array}{r}3.07 \\
6257\end{array}$ & $\begin{array}{r}23.4 \\
3198\end{array}$ & $\begin{array}{r}18 . \\
5\end{array}$ & 172 & $\begin{array}{r}218 . \\
3919\end{array}$ & 244 \\
\hline
\end{tabular}

Advances in Distributed Computing and Artificial Intelligence Journal

(C)Ediciones Universidad de Salamanca / cc by-nc-nd
ADCAIJ, Regular Issue, Vol.3 n.4 (2015)

http://adcaij.usal.es 
Table 3: Grain Size distribution Property of FSW AZ31B joint (without reinforcement).

\begin{tabular}{|l|r|r|r|r|r|r|r|r|r|}
\hline $\begin{array}{l}\text { Grain } \\
\text { Num- } \\
\text { ber }\end{array}$ & $\begin{array}{l}\text { Equiva- } \\
\text { lent Di- } \\
\text { ameter }\end{array}$ & $\begin{array}{l}\text { Orienta- } \\
\text { tion }\end{array}$ & \multicolumn{1}{l}{$\begin{array}{l}\text { Major } \\
\text { Axis }\end{array}$} & $\begin{array}{l}\text { Minor } \\
\text { Axis }\end{array}$ & $\begin{array}{l}\text { Perime- } \\
\text { ter }\end{array}$ & Area & $\begin{array}{l}\text { Min } \\
\text { Inten- } \\
\text { sity }\end{array}$ & $\begin{array}{l}\text { Mean } \\
\text { Intensi- } \\
\text { ty }\end{array}$ & $\begin{array}{l}\text { Max } \\
\text { Inten- } \\
\text { sity }\end{array}$ \\
\hline $\mathbf{1}$ & 3.191 & 25.19 & 3.54 & 2.99 & 9.70 & & & 202. & \\
& 538 & 141 & 9503 & 1304 & 7107 & 8 & 146 & 5313 & 239 \\
$\mathbf{2}$ & 0.977 & & 1.63 & & & 0. & & & \\
& 205 & 0 & 2993 & 0 & 0.5 & 75 & 233 & 242 & 247 \\
$\mathbf{3}$ & 1.381 & 90.00 & 3.41 & & & 1. & & 198. & \\
& 977 & 003 & 565 & 0 & 2 & 5 & 177 & 1667 & 230 \\
$\mathbf{4}$ & 0.977 & 90.00 & 1.63 & & & 0. & & 235. & \\
& 205 & 003 & 2993 & 0 & 0.5 & 75 & 232 & 3333 & 239 \\
$\mathbf{5}$ & 4.259 & - & 5.26 & 4.03 & 15.9 & 1 & & 233. & \\
& 538 & 23.7163 & 181 & 5167 & 3198 & 4.25 & 199 & 1228 & 252 \\
$\mathbf{6}$ & 2.585 & 66.20 & 3.47 & 2.47 & 7.81 & 5. & & 220. & \\
& 441 & 713 & 4742 & 0433 & 066 & 25 & 152 & 619 & 248 \\
$\mathbf{7}$ & 3.038 & - & 7.64 & 1.26 & 12.3 & 7. & & 225. & \\
& 254 & 86.7755 & 8602 & 0656 & 1066 & 25 & 176 & 8621 & 244 \\
$\mathbf{8}$ & 1.692 & 84.01 & 4.14 & 0.71 & & 2. & & 200. & \\
& 569 & 196 & 3543 & 4185 & 4 & 25 & 149 & 5556 & 243 \\
$\mathbf{9}$ & 3.141 & - & 7.20 & 4.94 & 13.1 & 7. & & 232. & \\
& 275 & 40.6765 & 3717 & 8255 & 0355 & 75 & 184 & 2581 & 247 \\
$\mathbf{1 0}$ & 1.871 & 80.00 & 2.44 & 1.45 & 5.12 & 2. & & 224. & \\
& 205 & 848 & 9648 & 995 & 132 & 75 & 195 & 0909 & 249 \\
\hline
\end{tabular}

\section{Conclusion}

The research work focuses on the development of machine learning algorithm for estimating the grain size distribution property of received matrix alloy and FSW AZ31B joint (without reinforcement) by using Python Programming. The various grain size parameters such as equivalent diameter, orientation, major axis, minor axis, perimeter, area, minimum intensity, maximum intensity and mean intensity were successfully determined. It is further observed from the Table 2 and Table 3 that the area, perimeter and equivalent diameter of the grain decreases after carrying out Friction Stir Welding process due to the refinement. So, it can be concluded that the machine learning approach can be easily incorporated in mate- 
rial science and manufacturing domain in order to reduce the cost and time of the experiment. It is also observed that there is loss of information by the observation of two and three dimensional metrics distribution such as aspect ratio, number density, total curvature, interface line and area density when conventional method is used for microstructure characterization but the application of machine learning overcomes these problems. The future work will deal with implementing this algorithm to the microstructure obtained by other characterization techniques also some work will be carried out on the development of a unique microstructure identifier known as microstructural fingerprint in order to classify micrographs. Machine learning can be further combined with the advanced microstructural metrics for improving the classification accuracy.

\section{References}

1. Aggour, K.S., Gupta, V.K., Ruscitto, D., Ajdelsztajn, L., Bian, X., Brosnan, K.H., Kumar, N.C., Dheeradhada, V., Hanlon, T., Iyer, N. and Karandikar, J., 2019. Artificial intelligence/machine learning in manufacturing and inspection: A GE perspective. MRS Bulletin, 44(7), pp.545-558.

2. Li, Z., Zhang, Z., Shi, J. and Wu, D., 2019. Prediction of surface roughness in extrusion-based additive manufacturing with machine learning. Robotics and Computer-Integrated Manufacturing, 57, pp.488-495.

3. García-Moreno, A.I., Alvarado-Orozco, J.M., Ibarra-Medina, J. and Martínez-Franco, E., 2020. Image-based porosity classification in Al-alloys by laser metal deposition using random forests. The International Journal of Advanced Manufacturing Technology, pp.1-19.

4. Kopper, A., Karkare, R., Paffenroth, R.C. and Apelian, D., 2020. Model Selection and Evaluation for Machine Learning: Deep Learning in Materials Processing. Integrating Materials and Manufacturing Innovation, pp.1-14.

5. Pothur Hema (October 24th 2019). Experimental Investigations on AA 6061 Alloy Welded Joints by Friction Stir Welding, Aluminium Alloys and Composites, Kavian Omar Cooke, IntechOpen, DOI: 10.5772/intechopen.89797. Available from: https://www.intechopen.com/books/aluminium-alloys-and-composites/experimental-investigations-on-aa-6061-alloywelded-joints-by-friction-stir-welding

6. Verma, S., Misra, J.P. and Popli, D., 2020. Modeling of friction stir welding of aviation grade aluminium alloy using machine learning approaches. International Journal of Modelling and Simulation, pp.1-8.

7. Hartl, R., Praehofer, B. and Zaeh, M.F., 2020. Prediction of the surface quality of friction stir welds by the analysis of process data using Artificial Neural Networks. Proceedings of the Institution of Mechanical Engineers, Part L: Journal of Materials: Design and Applications, 234(5), pp.732-751.

8. Srinivasan, K., Deepa, N. and PM, D.R.V., 2020. Realizing the Resolution Enhancement of Tube-to-Tube Plate Friction Welding Microstructure Images Via Hybrid Sparsity Model for Improved Weld Interface Defects Diagnosis. Journal of Internet Technology, 21(1), pp.61-72.

9. Subramani, V., Jayavel, B., Sengottuvelu, R. and Lazar, P.J.L., 2019. Assessment of microstructure and mechanical properties of stir zone seam of friction stir welded magnesium AZ31B through nano-SiC. Materials, 12(7), p.1044. 